\title{
Digital manipulation versus real one: learning and motivation in a case study on Storytelling
}

\author{
Assunta Tavernise ${ }^{a}$, Francesca Bertacchini $^{\mathrm{b}}$, Pietro Pantano ${ }^{\mathrm{c}}$, Eleonora Bilotta ${ }^{\mathrm{d}}$ \\ ${ }^{a}$ Laboratory of Cognitive Psychology, University of Calabria, Italy, assunta.tavernise@unical.it \\ ${ }^{b}$ Laboratory of Cognitive Psychology, University of Calabria, Italy, francesca.bertacchini@unical.it \\ ${ }^{c}$ Physics Department, University of Calabria, Italy, pietro.pantano@unical.it \\ dPhysics Department, University of Calabria,Italy, eleonora.bilotta@unical.it
}

\begin{abstract}
In this work, a Storytelling FabLab has been designed for the realization of virtual performances on a Shakesperian play in an elementary school. In this FabLab, many elements have been digitally manipulated: text, audio files, virtual actors on a 3D stage, and 3D Greek masks. Learning of contents and motivation have been assessed and compared to those of a traditional class working on the construction of real masks as artefacts. Regarding learning effectiveness, data show that there is no great difference between the score gained by the experimental group and the control one; however, results emphasize a high intrinsic motivation for both experimental and control groups. Moreover, qualitative results of both groups highlight the positive feeling of doing things reflecting user's own interest: pupils want to invent their own stories and realize them (physically or digitally).
\end{abstract}

Keywords: learning; education; motivation; laboratory; technology

\section{Introduction}

\subsection{Constructivism and manipulation}

In recent years, a fundamental theme of education has been the implementation of high-order cognitive skills through an active manipulation and construction of artefacts. In fact, starting from Piaget's (1970) and Vygotskij's (1978) constructivist principles, knowledge is not transmitted but built through hands-on activities, and learning experiences depend on action as the result of observation, manipulation, and interpretation of the world (Papert \& Harel, 1991). In a setting of experience based on manipulation, the acquisition of new meanings is the result of the relationship and interaction between the instruction material and the ideational one (anchoring ideas in cognitive structure), and simulation can provide the opportunities for a deeper cognition (Tavernise \& Bertacchini, 2017). Furthermore, digital activities based on manipulation can arise students' interest and competences, and young descents can become more proficient in school curriculum disciplines (Bertacchini, Bilotta, Pantano, \& Tavernise, 2012).

Virtual manipulation in digital fabrication and FabLab at school

Over the last decade, digital fabrication has emerged as a technology able to cause a great change in the traditional model of education (Gershenfeld, 2005). In particular, the opportunity of turning a digital design and manipulation of data into physical objects, translating "data into things", through computer-controlled fabrication systems (Bull, Knezek, \& Gibson, 2009; Berry et al., 2010) and tools for 3D printing (Mellis, Follmer, Hartmann, Buechley, \& Gross, 2013), provides students with the skills to support new constructivist learning processes. In fact, they can use powerful expressive tools based on virtual manipulation, being free to invent and follow their creativity (Blikstein, Fuhrmann, Greene, \& Salehi, 2012; Blikstein, 2013). In Fablab process, teachers act as facilitators, and students become the producer and the consumer of their educational artefacts, the "prosumers" (Bertacchini \& Tavernise, 2014). In this view, the Fabrication Lab as a centre, which allows individuals to design and make anything (Berry et al., 2010), becomes a "FabLab classroom" where materials such as paper, cardstock, and vinyl are used instead of metal and wood. Regarding this specific kind of classrooms, starting from the year 2008, when Stanford University promoted the FabLab@School project, the setting of FabLabs in K-12 schools spread all over the world (Bilkstein, 2013). The aim was to carry the digital fabrication activities at elementary school level to arise young students' interest and competences in science, math, and engineering (Alexander, Tillman, Cohen, Ducamp, \& Kjellstrom, 2013). The encouraging integration of engineering design into elementary classrooms was also confirmed by various researches 
(Burghardt \& Hacker, 2008; Burghardt \& Krowles, 2006; Akins \& Burghardt, 2006) that found that young students can become more mathematically proficient and more positively disposed towards the discipline. Furthermore, the combination of digital fabrication with engineering planning integrated other scientific disciplines into the laboratorial context, including programming and design (Astrachan, Hambrusch, Peckham, \& Settle, 2009), simultaneously encouraging students to Science, Technology, Engineering, and Mathematics (STEM)-related careers.

\subsection{Virtual Storytelling}

The ability to create stories is one of the essential skills for children as it can develop creativity, improve communication skills, and stimulate collaboration and interaction. Numerous ways to convey stories have been introduced with the rapid evolution of the technology, and scholars have laboured to offer a broad range of alternative tools such as serious games, virtual worlds, and 3D theatres (Barrett, 2006; Blikstein, 2013; Fridin, 2014; Bertacchini, Bilotta, Pantano, \& Tavernise, 2012). However, integrating virtual worlds for Storytelling in classrooms can be very daunting because the tool foresees a deep learning on the part of the teacher; most of the software are not suitably designed for children because the school do not have the digital resources or the computers. In spite of these problems, in recent years, many researchers have put a lot of effort into development to find the best means to help children to create and share their stories, and a huge number of possible designs have been realized. Regarding digital environments as theatrical stages, "virtual theatres" have been used as a useful setting to link technology to narrative elements (Adamo, Bertacchini, Bilotta, Pantano, \& Tavernise, 2010). In particular, the virtual space has become not only a tool for representation but also for action plus interaction, and the user has been a scriptwriter, an actor, a director, or a spectator (Machado, Prada, Paiva, 2000; Cavazza \& Donikian, 2008). In these 3D places, the user can both enjoy herself/himself having an active role, exploring/creating/elaborating the content, and "learning by doing".

\subsection{Purpose of the Research}

In this case study, the aim of the research was to compare the learning and motivation in two laboratories devoted to Storytelling, a traditional (based on the manipulation of physical materials as a paper copy of the script, paperboard, colours, and scissors) and a digital one (based on the manipulation of virtual materials as a digital copy of the script and software). In particular, the laboratories had the objective of both learning/elaborating the script of a Shakespearian comedy ("A Midsummer Night's Dream"), and realizing masks to be used during the performance as in Greek tradition. A qualitative investigation of the experience was also carried out. Regarding software, in the digital laboratory, personal computers were endowed with Face3D, a tool able to manipulate digital materials connected with the realization of virtual actors and performances, already used in successful experimentations with children.

As shown in the previous paragraphs, the reference theory was constructivism: according to constructivist hands-on model, high-order cognitive skills are implemented through an active manipulation and construction of artefacts. Moreover, in recent years, the translation of "data into things" has spread in classrooms, transforming them in FabLabs and reaching good results in terms of learning and motivation. Hence, research questions were the following: are there different knowledge results after the use of a 3D environment comprising a virtual exploration and manipulation of objects, in comparison with those obtained by a control group after a real manipulation? Are drama contents simpler to learn if they are conveyed by technological devices? Are students motivated by the use of technology in an activity which is not present in the school curriculum? What characteristics are highlighted by students' qualitative opinions? More in general, if FabLabs are helpful for the improvement of STEM skills, can they be functional also for narrative thought? In fact, if digital fabrication activities are carried out at an elementary school level to arise students' interest and skills in scientific subjects, the possibilities of storytelling are not explored adequately. Another novelty of this research is represented by the fact that both group manipulated contents, virtual versus real ones, whereas experimentations usually foresee a manipulative experimental group versus a no-manipulative one.

The expected results concern digital hands-on activity as a valid support for improving elementary school students' knowledge, and a positive consideration of digital manipulation in an emerging technology by students. Satisfaction and motivation for the use of a technology-enhanced setting could provide the expectation of a good learning. Moreover, even if previous studies highlight some differences in gender results, expected data should not underline a wide dissimilarity. Of course, taking into account the size of the sample, data can be considered as a preliminary consideration for further analysis and developments. Other limitations are present in the "Discussion" paragraph.

\section{Methodology}

\subsection{Research participants}

The experimental sample consisted of 40 students, aged between 9 and 10 years; the control group consisted of 40 children of the same age (Table 1). In each group, 20 were females and 20 were males. Students were from the fourthand fifth-grade classes of an elementary school in Reggio Calabria (Italy), and they were randomly assigned to one of the two laboratories. 
To establish whether subjects were comfortable with computer, a pre-questionnaire was administrated; all declared to be familiar with the device and to have used it in previous instructional activities. The research was carried out in students' classroom, where portable computers were brought and used; in the classroom, two printers were fixed and accessible for laboratory activities. Experience coexisted with curriculum school courses, and it took place in the afternoon. Research settings were rigorously predisposed.

\begin{tabular}{lll}
\multicolumn{3}{c}{ Table 1. Subjects' mean age and standard deviations. } \\
\hline $\mathbf{N}$ & Age Mean (9-10) & SD \\
\hline Experimental Group & & \\
Male 20 & 9.20 & 0.41 \\
Female 20 & 9.36 & 0.49 \\
\hline & & \\
\hline Control Group & & 0.49 \\
Male 20 & 9.30 & 0.49 \\
\hline
\end{tabular}

\subsection{Research materials}

For the realization of the experiment, different materials were used. In the experimental laboratory, the following materials were utilized:

- a digital copy of the script of the Shakespearian comedy “A Midsummer Night's Dream”;

- $\quad$ portable personal computers;

- "Word" software for the digital manipulation of the text;

- a recording device for the virtual manipulation of audio files with the students' voices performing the comedy;

- Face3D software for the implementation and animation of the virtual performance related to the elaborated script;

- The software Pepakura design 3 to import the free geometric models of masks and print them;

- Two printers.

In the traditional laboratory, students used the following materials:

- a paper copy of the script of the Shakespearian comedy "A Midsummer Night's Dream" was used; A4 Paper sheets (30 $21 \mathrm{~cm}$.), pens, pencils, rubbers for the reduction/elaboration of the script based on the Shakespearian comedy;

- paperboard, colours, and scissors for the realization of real masks.

Furthermore, researchers used motivation and learning questionnaires, further details on software, digital devices, and questionnaires are present in the following paragraphs.

\subsubsection{Software and tools}

In this study, a Storytelling software called Face3D (Bertacchini et al., 2007) has been used for the virtual manipulation of digital contents, aiming at the realization of the virtual actors, performance, and masks. Face3D is a user-friendly authoring system that allows the realization of virtual performances with pedagogical agents as $3 \mathrm{D}$ Talking Heads.

The software is composed by three graphical user interfaces (GUIs): Face3DEditor for modelling virtual actors, Face3DRecorder for animating them, and Virtual Theatre for the performance of the theatrical piece (Tavernise, 2012). A very simple parametric basic model (Figure 1) can be changed for the generation of different 3D Talking Heads (Figure 1) that can also be printed as or 3D objects. The starting model is constituted by a low number of vertices (131), and seven facial emotions (anger, surprise, sadness, fear, joy, disgust, and attention) can be visualized and modelled. Talking Heads are also capable of random movements of head and eyes (the "noise" function inspired by Perlin's studies; Perlin, 1997).

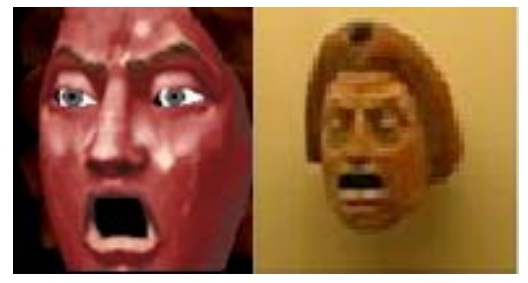


Regarding the GUIs, the main characteristics are the following (Figure 2):

- Face3DEditor allows the facial 3D modelling and manipulation of virtual actors. This interface offers the opportunity to insert a drawing or a picture under the basic parametric model, and to move the vertices to model the character, the mask, or the virtual actor.

- Face3DRecorder allows the animation of the virtual actors' facial expressions as well as the synchronization of these facial expressions with pre-recorded files of speech.

- Virtual Theatre allows the realization of a performance with the animations of different virtual actors.

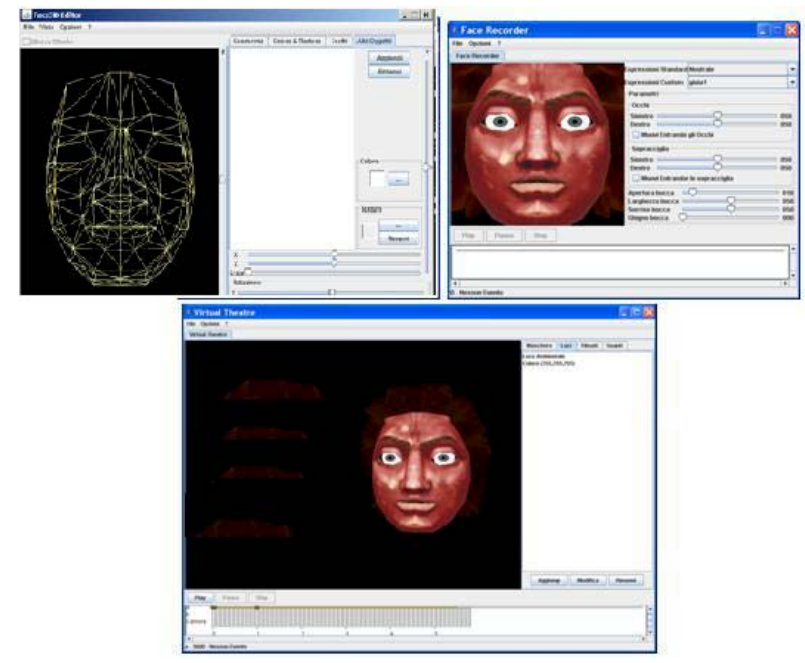

Figure 2 The GUIs of Face3D (Face3DEditor, Face3DRecorder, and Virtual Theatre).

For the realization of the audio files, a recording device has been used. In fact, subjects had to record the playing of each sentence of the script, upload the recording on the software, and synchronize it with the facial expression of the 3D Talking Head.

The used portable personal computers had a screen resolution of 1280800 mega pixel to have a good visualization of virtual materials.

The software Pepakura design 3 (http://www.tamasoft.co.jp/pepakura-en/) has been used to physically realize the Face3D Talking Heads by traditional printers. It allows the importing of free geometric models such as 3D Talking Heads as models to assemble, as well as their printing. Pepakura Designer can translate 3D objects into a 2D printable format, supporting some 3D file formats from software such as 3D Studio, LightWave, and Softimage.

\subsubsection{Questionnaires}

After a brief pre-questionnaire on the familiarity with computers, quantitative data on learning and motivation have been gathered through the followings:

- a learning questionnaire consisting of 15 closed-ended questions on the knowledge of the comedy "A Midsummer Night's Dream";

- a motivation questionnaire on subjects' interest/enjoyment, perceived competence, effort/importance, and value/usefulness, for the learning through the manipulation of digital/physical objects in the proposed Laboratory settings;

Individual interviews on children's opinions regarding the laboratory experience have been carried out to collect qualitative data.

Regarding learning questionnaire, each question had three answer possibilities, 1 point has been scored for each correct answer and 0 for each incorrect one, for a maximum of 15 points. The 15 multiple choice questions addressed various topics, from the content of the comedy to the characters' peculiarities. Examples of the questions are the following:

1) What does use Puck for his spell?

A potion

An apple

A love flower juice

2) Bottom's head is transmuted in the head of

A sheep 


\title{
Digital manipulation vs. real one: learning and motivation in a FabLab on Storytelling
}

\author{
Tavernise, Bertacchini, Pantano, Bilotta.
}

A donkey

A cow

3) Oberon is

In love and he want to marry Titania

An actor

The fairy king

Regarding the motivation questionnaire, 25 items have been adapted from the Likert scale Intrinsic Motivation Inventory (IMI), reported as reliable and valid by McAuley, Duncan, and Tammen (1987). IMI has also been used in numerous experiments related to intrinsic motivation and self-regulation (Plant \& Ryan, 1985; Ryan, Koestner, \& Deci, 1991; Ryan, Mims, \& Koestner, 1983). Since past research have demonstrated that the inclusion or exclusion of specific subscales appears to have no impact on the others, it is suggested that experimenters choose the subscales applicable to the issues they are exploring (Liu, Horton, Olmanson, \& Toprac, 2011). For this reason, the following subscales have been used: interest/enjoyment, perceived competence, effort/importance, and value/usefulness (please see Appendix). In particular, the used items aimed at assessing intrinsic motivation after the manipulation of real and virtual contents in the designed settings (experimental and control ones). In the selected subscales, some statements were negative and marked with (R); the four subscales on a seven-point Likert scale had 1 meaning "not all true" and seven "very true".

Regarding children's opinions on the experience, individual interviews have been administrated at the end of the Laboratory.

\section{Procedure}

The laboratory settings and activities were designed, and a teacher implemented the learning questionnaires on the Shakespearian theatrical piece “A Midsummer Night's Dream”.

Research included three stages for the two laboratories. In the experimental Laboratory, the group had the opportunity to experience different aspects of the performance, from the learning and re-writing of the script, to the digital manipulation of the look of the actors, to the recording of audio files and printing of the masks; in particular: a) some introductory information on theatrical performances, Shakespeare, and characters' study were provided; b) students learned and re-wrote the script for adapting it to the new performance; c) children manipulated virtual objects (as audio files and software virtual actors) for the realization of the virtual theatre performance; c) students realized the real masks digitally (Figure 3), printing them; d) subjects compiled a knowledge questionnaire and a motivation test, and participated to an interview.
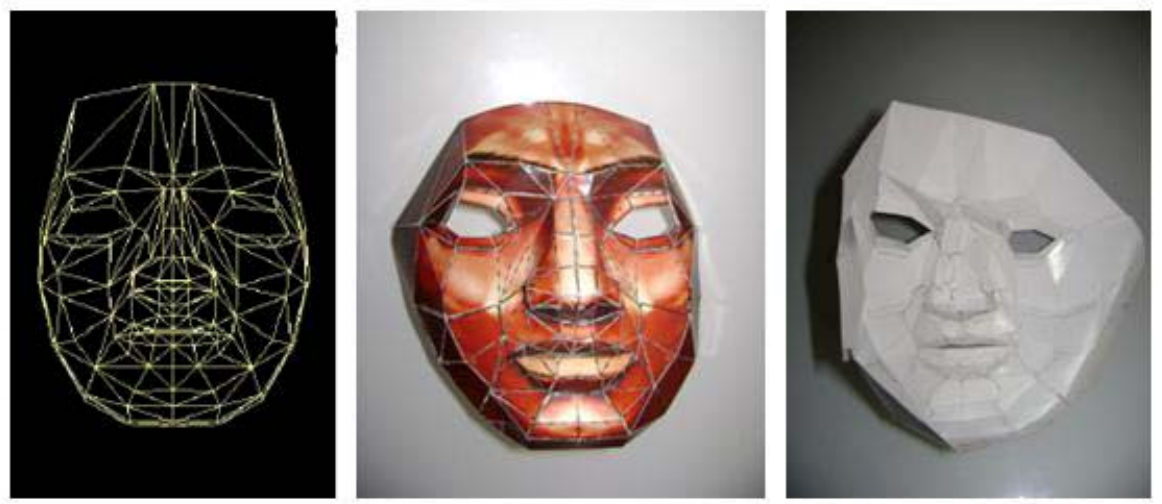

Figure 3. Digital fabrication: from the 3D model to the tangible mask (front and back).

In the control Laboratory, the second group worked as in a traditional class for the realization of a theatrical performance, learning the text and realizing real masks as artefacts. Firstly, as in the experimental group, after some introductory information on theatrical performances, Shakespeare, and characters' study, students learned and re-wrote the script for adapting it to the new performance. Afterwards, subjects realized the physical masks (Figure 4) using paperboard, colours, and scissors. At the end, subjects compiled a knowledge questionnaire and a motivation test, and participated to an interview.

Both Laboratories had a duration of 12 hours. 

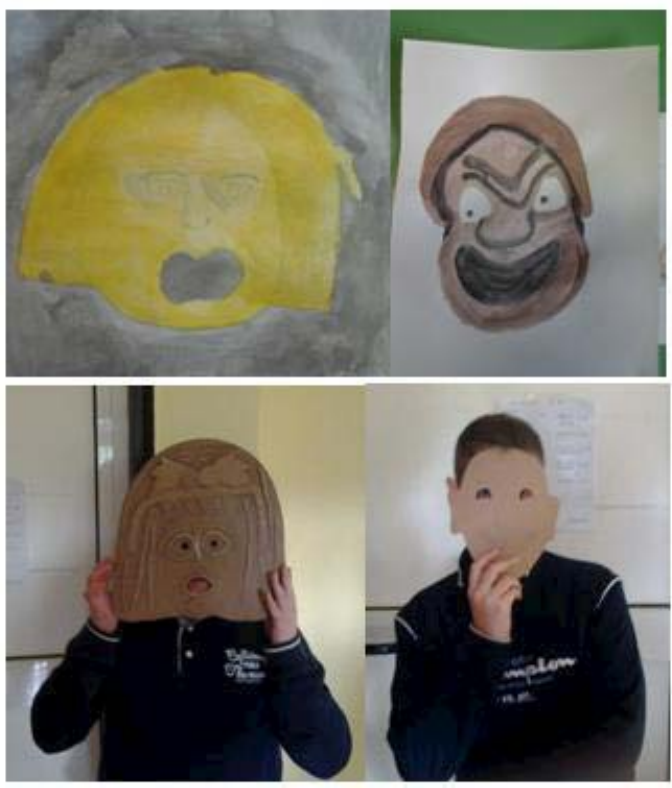

Figure 4. Traditional hands-on learning: from the drawing to the real mask.

Strictly regarding the experimental activity of digital fabrication in the context of storytelling, it involved the construction of paper-based masks to be worn during the students' performance, for both groups. In particular, regarding the experimental group, subjects digitally managed the wire-frame of ancient Greek masks present in the library of the software. Then, participants used the software Papekura to realize the masks to print.

Regarding learning questionnaires, there has not been an administration and analysis of pre- versus post-knowledge questionnaire, since children did not know any information on the author and his works (foreign literature is not present in Italian curriculum). Results obtained in learning and motivation questionnaires by experimental group were compared to those obtained by control one using SPSS version 22.

\section{Results}

\subsection{Knowledge results and motivation}

Regarding learning effectiveness, results show that there is no great difference between the score gained by the experimental group and the control one. The scores obtained by the experimental group versus control one were analysed using paired sample t-tests to determine whether there was an effect because of the treatment. For the experimental group, the knowledge score had a mean of 12.9 (SD 1.35) for the experimental group, and a mean of 13.27 (SD 1.69) for the control one, $\mathrm{t}(39)-1.861, \mathrm{p} 0.01$.

Regarding gender differences, male subjects gained a score slightly higher with respect to the female participants, in both groups. In particular, in the experimental group, male score had a mean of 13.35 (SD 1.09) and female one of 12.45 (SD 1.47); in control Group, the male subjects' mean was 13.9 (SD 1.55), whereas female subjects' one was 12.65 (SD 1.63). Results are clearly shown in Table 2.

Table 2. Mean and standard deviation of learning scores.

\begin{tabular}{lll}
\hline Male & Female & Total \\
\hline Learning scores Mean/SD & Mean/SD & Mean/SD \\
Experimental Group 13.35/1.09 & $12.45 / 1.47$ & $12.90 / 1.35$ \\
Control Group 13.90/1.55 & $12.65 / 1.63$ & $13.27 / 1.69$
\end{tabular}

With regard to motivation analysis, the IMI test as a whole had an alpha value of 0.718 . Regarding the correlations between the IMI subscale results and the knowledge scores, in the experimental group, subjects' self-report of interestenjoyment was not significantly related to learning score $(\mathrm{r}-.026, \mathrm{p} 0.01)$ (Table 3). Thus, it cannot be considered true that the more interest-enjoyment subjects reported, the more students obtained a high score. However, since the interest/enjoyment subscale can be considered as the self-report measure of intrinsic motivation, the obtained interestenjoyment single score (45, 75 in an assessment between 39 and 49, with 49 as the major possible score) could denote a 
very high motivation in using the proposed technology. Subjects' self-rated Perceived Competence was also not significantly related to learning scores ( $\mathrm{r} .003$, p 0.01). Not surprisingly, also Effort/Importance and learning scores were not related positively ( $\mathrm{r} .022$, p 0.01 ), as well as Value/Usefulness from this measure was marginally negatively related to learning scores ( $\mathrm{r}-.178, \mathrm{p}$ 0.01). Also in the case of control group, both subjects' self-report of interestenjoyment were not significantly related to the learning score $(\mathrm{r} .012, \mathrm{p} 0.01)$, and Perceived Competence related to knowledge results $(\mathrm{r}-.086, \mathrm{p}$ 0.01). Effort/Importance and learning scores were not related significantly $(\mathrm{r} .141, \mathrm{p}$ $0.01)$, as well as Value/Usefulness and learning scores ( $\mathrm{r}-.002, \mathrm{p} 0.01)$.

Table 3. Correlations between the IMI subscale results and learning scores.

\begin{tabular}{lll}
\hline \multicolumn{2}{l}{ Motivation subscales } & \\
\hline Interest/Enjoyment & Perceived Comp. & Effort Value \\
Learning Scores & & \\
\hline Experimental -0.26 & .003 & $.022-.178$ \\
Control.012 & -.086 & $.141-.002$ \\
\hline${ }^{*} 0.01$ & & \\
\hline
\end{tabular}

\subsection{Quality of learning experience}

Regarding the qualitative aspects of the research, as explained in "1.2.2 Questionnaires", individual interviews were carried out. Experimental and control subjects participated, and questions regarded children's opinions on the laboratory experience. In particular, questions focused on Perceived Usefulness, Ease of Use, Enjoyment, and Suitability for the task (appropriateness for learning) as those used in literature (Figure 4). However, given the age of the sample, questions were very simple (e.g. Did you feel comfort during the laboratory? Is this kind of laboratory lesson useful? Were tools easy to use? Did you understand immediately what to do? Was this activity boring to do? Did you enjoy it? What did you enjoy most? Was the activity difficult to carry on? Did you find support in performing your task? Who gave you support?).

\begin{tabular}{|l|l|}
\hline Variable & Adapted from \\
\hline Perceived Usefulness & $\begin{array}{l}\text { Lee et al. (2005), Bourgonjon et al. } \\
(2010)\end{array}$ \\
\hline Ease of Use & Lee et al. (2005), Saadé \& Bahli (2005) \\
\hline Enjoyment & Lee et al. (2005) \\
\hline Attitude & Hu et al. (2003) \\
\hline Suitability for the task & Inserted by the authors \\
\hline
\end{tabular}

Figure 4. Measurement scale adapted from literature.

Open answers were audio-recorded and then transcribed for data collection. During the interviews, children had the possibility to freely indicate their grade of preference of the activity, but a Likert scale was not used (the sample would have not fully understood the proposed range). The qualitative data were considered as additional information to the quantitative ones, to better understand some nuance of the felt experience. As the main results confirm, the majority of the experimental sample affirmed to perceive the used technological devices as comfortable and useful for the proposed activities. In particular, regarding the experimental group, the provided 3D materials, and in general animations and interactive elements were appreciated. However, low satisfaction was shown for the quality of the manipulative contents in comparison with advanced videogames realized for commercial reasons, where 3D Graphics has reached very high levels (in the system, models have a low number of polygons and vertices to allow a simple manipulation for children's activities). Regarding the suitability of the application for learning, the majority of the users appreciated the system, declaring that outputs adequately support the goal. In general, the activity was felt as enjoying and engaging, and the systems was considered as pleasant.

Control group participants reasoned on the positive and negative aspects of the experience, and good reviews on the educational experience were present. Subjects mainly commented the realization of drawings and paperboard masks as very amusing. The negative aspects regarded the hour of the day (afternoon) and questionnaires (boring).

No indications of rejection of both educational paths were present. Furthermore, the possibility to explore digital possibilities for the experimental group, or freedom to do things following users' own interests in the control group (e.g. subjects realized Puck's face as they wished, following their creativity) have been mentioned. 


\section{Digital manipulation vs. real one: learning and motivation in a FabLab on Storytelling}

Tavernise, Bertacchini, Pantano, Bilotta.

\section{Discussion}

The results of this study on storytelling showed that, regarding learning scores and motivation, there was no significant difference between students' learning when subjects carry out virtual or real manipulation. The findings of this study emphasize not only very positive results in learning but also a high intrinsic motivation for both experimental and control group. In fact, even if the extraordinary power of narration in all its forms is unquestionable, data on motivation allow new reflections. Considering that the interest/enjoyment subscale as the self-report measure of intrinsic motivation, the score obtained by experimental group could be considered as an index of a very high motivation in using the proposed technology. In general, regarding challenges and potentials of the approach, technology-enhanced settings can be highly motivating contexts, giving the opportunity to make, build, share creations, and develop cross skills as the learning of analysis/problem-solving. From an educational model where books, culture resources, and laboratories can be accessed only by a restricted number of people, this new approach allows a potential unlimited number of students and a distant learning. In fact, digital fabrication process can provide students flexible, engaging, and different ad-hoc built learning experiences. Furthermore, being good at the technological activity could help students not only to learn better Shakespeare's work but also to gain the 21 st century cognitive skills (the higherorder thinking skills, that involve critical thinking, problem solving, creativity, communication, collaboration, and digital literacy) (Drigas \& Karyotaki, 2014). Moreover, given the qualitative findings of this study, some digital fabrication components could be stressed to offer a more enjoyable experience. Since the majority of the digital fabrication sample stated to perceive the used technological devices as comfortable, useful, and suitable for the proposed activities, new designs could provide the opportunity of extended and richer interactions. In comparison with control group, the focus of interviews was very different because the highlighted negative aspects regarded a change in activity time and the questionnaires as boring. However, an interesting aspect concerns the freedom to do things following students' interests for both groups: they want to invent their own stories and realize them (physically or digitally).

Moreover, it is important to highlight that the acquired skills concern a group aged 9-10 years and, even if digital fabrication has already been introduced into elementary school, the achieved learning objectives are still surprisingly. Therefore, it must be highlighted that advanced laboratories (virtual ones and Fablabs) should opportunely be planned by professionals because they have the fundamental aim to attract not only the science-vocational types but also students who just wanted to try a project with technology, or enhance their skills.

Finally, this pilot study has showed some limitations: the measured activity in the two groups lasted only 12 hours, whereas activities lasting a much longer time could have a different result. Moreover, the study was limited to one elementary school located in a specific city of Southern Italy, so findings may not be fully generalizable without comparisons. Sample consisted of users familiar to technology, and different results could be obtained with inexperienced users. Moreover, qualitative opinions were subject to reporting bias. Regarding cognitive features, analysis, creation, and application (intending analysis as the breaking of material into its constituent parts and detecting how the parts relate to one another and to an overall structure or purpose, with students being expected to analyse before they create) (Krathwohl, 2002), they have not been investigated in the present research. Finally, the preferred learning styles could be correlated to knowledge data.

\section{Conclusions}

Starting from digital fabrication concept, this work dealt with the assessment of learning effectiveness in relation to intrinsic motivation in a FabLab devoted to Storytelling. In fact, FabLabs can be seen not only as places devoted to the spreading of scientific concepts or the training future scientist, engineers, and mathematicians. In this view, to be fluent with technology can be considered not a vocational skill but a knowledge crossing disciplines and valuable for all citizens. Regarding research questions, in this case study, there was no significant difference between students' learning when subjects carry out virtual or real manipulation. In this view, the use of technology could be taken into account not for a simpler learning of drama contents but above all for implementing motivation (as quantitative and qualitative analyses reported). Hence, digital fabrication as emergent technology can play a fundamental role in students' cognitive development as long as it is included successfully in school curriculum. In fact, children can acquire a skill variety in unrelated fields (cross multiple skills to use in the performance of multiple different tasks). Students' cognitive skills can be developed through a well-defined educational framework and ad-hoc built activities that could include not only STEM topics; however, further experimentations are needed.

\section{Appendix}

Adaptation from the Intrinsic Motivation Inventory (IMI)

Interest/Enjoyment

I enjoyed doing this activity very much.

This activity was fun to do.

I thought this was a boring activity. (R) 
This activity did not hold my attention at all. (R)

I would describe this activity as very interesting.

I thought this activity was quite enjoyable.

While I was doing this activity, I was thinking about how much I enjoyed it.

Perceived Competence

I think I am pretty good at this activity.

I think I did pretty well at this activity, compared to other students.

After working at this activity for a while, I felt pretty competent.

I am satisfied with my performance at this task.

I was pretty skilled at this activity.

This was an activity that I couldn't do very well. (R)

Effort/Importance

I put a lot of effort into this.

I didn't try very hard to do well at this activity. (R)

I tried very hard on this activity.

It was important to me to do well at this task.

I didn't put much energy into this. (R)

Value/Usefulness

I believe this activity could be of some value to me.

I think that doing this activity is useful for learning Shakespeare's work

I think this is important to do because it can help me to learn Shakespeare's work

I would be willing to do this again because it has some value to me.

I think doing this activity could help me to learn Shakespeare's work

I believe doing this activity could be beneficial to me.

I think this is an important activity.

\section{References}

Adamo, A., Bertacchini, P. A., Bilotta, E., Pantano, P., \& Tavernise, A. (2010). Connecting art and science for education: learning through an advanced virtual theater with 'Talking Heads'. Leonardo Journal, MIT press, 43(5), $442-448$.

Akins, L., \& Burghardt, D. (2006). Improving K-12 mathematics understanding with engineering design projects. Paper presented at the 2006 Frontiers in Education Conference, San Diego.

Astrachan, O., Hambrusch, S., Peckham, J., \& Settle, A. (2009). The present and future of computational thinking. Paper presented at the 40th ACM technical symposium on Computer science education, Chattanooga, TN, USA.

Barrett, H. (2006). Researching and Evaluating Digital Storytelling as a Deep Learning Tool. In C. Crawford et al. (Eds.), Proceedings of Society for Information Technology \& Teacher Education International Conference 2006 (pp. 647-654).

Bertacchini, P.A., Bilotta, E., Pantano, P., Battiato, S., Cronin, M., Di Blasi, G., Talarico, A., Tavernise, A. (2007). Modelling and Animation of Theatrical Greek Masks in an Authoring System. Paper presented at the Eurographics Italian Chapter 2007 Conference, Trento (Italy), pp. 191-198.

Bertacchini, F., Bilotta, E., Pantano, P., \& Tavernise, A. (2012). Motivating the learning of science topics in secondary school: A constructivist edutainment setting for studying Chaos, Computers \& Education, 59 (4), $1377-1386$. http://dx.doi.org/10.1016/j.compedu.2012.05.001.

Bertacchini, F., \& Tavernise, A. (2014). Knowledge sharing for Cultural Heritage 2.0: prosumers in a "digital agora", International Journal of Virtual Communities and Social Networking (IJVCSN), (6)2, 24-36. Hershey, USA: IGI Global Publishing.

Blikstein, P. (2013). Digital Fabrication and 'Making' in Education: The Democratization of Invention. In J. WalterHerrmann \& C. Büching (Eds.), FabLabs: Of Machines, Makers and Inventors. Bielefeld: Transcript Publishers.

Blikstein, P., Fuhrmann, T., Greene, D., \& Salehi, S. (2012). Bifocal modeling: mixing real and virtual labs for advanced science learning. Paper presented at the 11th International Conference on Interaction Design and Children, Bremen, Germany.

Bourgonjon J., M. Valcke, Soetaert R., Schellens T. (2010), Students' perceptions about the use of video games in the classroom, Computers \& Education, 54, 1145-1156.

Bull, G., Knezek, G., \& Gibson, D. (2009). Editorial: A rationale for incorporating engineering education into the teacher education curriculum. Contemporary Issues in Technology and Teacher Education, 9(3), 222-225.

Burghardt, D., \& Hacker, M. (2008). Development of a math infusion model for middle school engineering/technology education. Paper presented at the $38^{\text {th }}$ ASEE/IEEE Frontiers in Education Conference, Saratoga, NY.

Burghardt, M.D., \& Krowles, C. (2006). Enhancing mathematics instruction with engineering design. Paper presented at the American Society for Engineering Education Annual Conference, Pittsburgh, PA. Retrieved from http://soa.asee.org/paper/conference/paper-view.cfm?id1070. 
Cavazza, M., \& Donikian, S. (2008). Virtual Storytelling: Using Virtual Reality Technologies for Storytelling. Paper presented at the 4th International Conference, ICVS 2007.

Alexander, C., Tillman, D., Cohen, J. D., Ducamp, G. J., \& Kjellstrom, W. (2013). Piloting Innovative Learning Experiences: Measuring Outcomes of Digital Fabrication Activities across Five Classes. Paper presented at the Society for Information Technology \& Teacher Education International Conference, 1165-1173.

Drigas, A., \& Karyotaki, M. (2014). Learning Tools and Applications for Cognitive Improvement. International Journal of Engineering Pedagogy, 4(3), 71-77.

Gershenfeld, N. (2005). Fab: The coming revolution on your desktop - from personal computers to personal fabrication. New York, NY: Basic Books.

Hu, P. J., Clarkb, T. H. K., \& Mab, W.W. (2003). Examining technology acceptance by school teachers: a longitudinal study, Information \& Management, 41, 227-241.

Krathwohl, D. (2002). A revision of Bloom's taxonomy: An overview. Theory Into Practice, 41(4), 212-218.

Lee, M.K.O., Cheung, C.M.K., \& Chen, Z. (2005), Acceptance of Internet-based learning medium: the role of extrinsic and intrinsic motivation, Information \& Management 42, pp. 1095-1104.

Liu, M., Horton, L., Olmanson, J., \& Toprac, P. (2011). A study of learning and motivation in a new media enriched environment for middle school science. Educational Technology Research and Development, 59(2), 249 - 265.

Machado, I., Prada, R., Paiva, A. (2000). Bringing Drama into a Virtual Stage. Paper presented at the III International Conference on Collaborative Virtual Environments, San Francisco, USA.

McAuley, E., Duncan, T., \& Tammen, V. V. (1987). Psychometric properties of the Intrinsic Motivation Inventory in a competitive sport setting: A confirmatory factor analysis. Research Quarterly for Exercise and Sport, 60, 48-58.

Papert, S., \& Harel, I. (1991). Constructionism. New York: Ablex Publishing Corporation.

Perlin, K. (1997). Layered compositing of facial expression. ACM/SIGGRAPH Technical Sketch, $\mathrm{http}: / / \mathrm{mrl}$.nyu.edu/perlin/experiments/facedemo.

Piaget, J. (1970). The Science of Education and the Psychology of the Child. NY: Grossman.

Plant, R. W., \& Ryan, R. M. (1985). Intrinsic motivation and the effects of self-consciousness, self-awareness, and egoinvolvement: An investigation of internally-controlling styles. Journal of Personality, 53, 435-449.

Ryan, R. M., Koestner, R., \& Deci, E. L. (1991). Varied forms of persistence: When free-choice behavior is not intrinsically motivated. Motivation and Emotion, 15, 185-205.

Ryan, R. M., Mims, V., \& Koestner, R. (1983). Relation of reward contingency and interpersonal context to intrinsic motivation: A review and test using cognitive evaluation theory. Journal of Personality and Social Psychology, 45, 736-750.

Saadé, R., \& Bahli, B. (2005). The impact of cognitive absorption on perceived usefulness and perceived ease of use in on-line learning: an extension of the technology acceptance model. Information \& Management, 42, 317-327.

Tavernise, A. (2012). Narrazione e Multimedia - Ricerca educativa e applicazioni didattiche. Roma: Ed. Meti.

Tavernise, A, \& Bertacchini, F. (2017). Learning through Drama: Guidelines for Using Storytelling and Virtual Theatres in Classrooms. Journal of Education Research, 10(2), pp. 163-174.

Vygotsky, Lev (1978). Mind in Society. London: Harvard University Press. 